S sciendo

\title{
«Existir» e «existência» em Platão
}

José Trindade Santos

Universidade de Lisboa

Disputatio No. 8

May 2004

DOI: $10.2478 /$ disp-2004-0003

ISSN: 0873-626X 
Disputatio 16, May 2004

\title{
«Existir» e «existência» em Platão
}

\author{
José Trindade Santos \\ Universidade de Lisboa
}

\begin{abstract}
Parmenides' argument in the Way of Truth and Plato's theory of Forms are usually seen as mighty metaphysical constructions. But what if they are motivated by the semantic complexity of the Greek verb 'be'? This is the approach followed throughout this paper, mostly dealing with the debate on the emergence of a separate existential reading of 'einai,' and the problems arising from the use of the Latin verb 'existere' to translate it. The analysis of some sophistic puzzles provides examples of this fused reading of the verb. They suggest that Plato's philosophical program was intended as a correction of current sophistic views on reality and discourse, both through his theory of Forms, and the analysis of being and not being, carried out in the Sophist.
\end{abstract}

1. O problema posto por noções como «existir» e «existência», em textos de filosofia grega clássica, nomeadamente em Platão, é complexo e justifica uma abordagem que o torne acessível a leitores de filosofia que não compreendam grego clássico. É esse o objectivo do nosso estudo ${ }^{1}$.

1.1. A tradução do verbo ser, do grego clássico para as línguas modernas, põe uma constelação de problemas. O primeiro é o problema linguístico, da diversidade de sentidos que o verbo einai acumula. O segundo é o problema filosófico, resultante desta polissemia. Encontramo-lo condensado na tese de Parménides sobre o ser, cuja influência persiste na filosofia grega posterior, particularmente nas concepções sofísticas sobre linguagem e realidade e na crítica a que Platão e Aristóteles as submetem.

${ }^{1}$ Este texto foi motivado pela leitura de «A existência em Platão», in António Pedro Mesquita, Platão e o Problema da Existência, Lisboa 2003, pp. 17-109. 
O terceiro problema inverte a perspectiva dos anteriores, tendo a ver com o modo como são entendidos por um leitor actual. Reside na especificidade da leitura existencial, em relação com os outros sentidos do verbo, em particular, na obra platónica. Um quinto, a que não prestaremos atenção, será o do problema filosófico da existência. Vamos abordálos por esta ordem.

1.2. O verbo «ser», em grego, einai, é correntemente usado com quatro sentidos, para nós totalmente distintos, mas, para um grego clássico, dificilmente separáveis:

1. Predicativo - A é B;

2. Existencial - A existe;

3. Identitativo - A é A;

4. Veritativo - A é verdade.

É a condensação destes quatro sentidos do verbo que vemos no poema Da natureza. Parménides usa «é», «ser» e «o ser» (to einai, to eon) com todos estes sentidos ${ }^{2}$, ao colocar na boca da deusa um complexo argumento (fragms. 2, 3, 6, 7, 8.1-49), expressando a unidade lógica, epistemológica e ontológica de uma entidade englobante a que chama «Ser». Nela se acha expressa uma única realidade/verdade, correspondente ao único pensamento possível sobre a única «Coisa» ${ }^{3}$ pensável e dizível: o ser. Esta unidade e identidade fica cunhada no fragmento 3 do Poema $-\ll \mathrm{O}$ mesmo é pensar e ser» ${ }^{4}-$, sendo confirmada adiante, em 6. 1-2, 8. 3436.

${ }^{2}$ Adiante notaremos o desacordo dos intérpretes acerca dos sentidos a atribuir às utilizações que o Eleata faz do verbo «ser». Mas não há dúvida de que a posteridade fará incidir a sua crítica na dificuldade na distinção do «é» da existência do da predicação (Mill, Logic, i.iv.i; vide C. Kahn, «The Greek Verb «To Be» and the Concept of Being», Foundations of Language, 2, 1966, p. 247).

${ }^{3} \mathrm{Em} \mathrm{2.7}$, expressa pela forma participial, surge to mê eon - o não ser - $\mathrm{e}$ adiante (6.1) to eon. A língua grega exprime esta entidade abstracta antepondo o artigo neutro - to - à forma do infinitivo, ou do particípio do verbo: «o pensar», «O ser», «o dizer», etc.

${ }^{4}$ Uma tradução literal do frgm. 3, arcaizante e áspera, em português, seria «O mesmo é para pensar e ser» (explorando o antigo sentido dativo do verbo: vide J. Burnet, L'Aurore de la Philosophie Grecque, Paris, 1970, p. 200, n.3). Mas a construção é justificada por um paralelo metafórico em Empédocles: poros esti 
1.2.1. No esquema acima, os usos 1 e 3 são incompletos, por exigirem complemento, enquanto os 2 e 4 se mostram completos, não requerendo qualquer explicitação ulterior. Esta diferença parece indiciar uma primeira distinção dos sentidos do verbo, mas é um erro concluir que só um uso completo implica as leituras existencial ou veritativa ${ }^{5}$. Pois muitos casos de uso completo são, ou podem ser lidos como, incompletos, pelo facto de o predicado se achar elidido (por exemplo, «João lê», em vez de «João lê livros»).

A grande diferença, em relação ao uso do verbo nas línguas actuais, reside na fusão ${ }^{6}$ dos quatro sentidos, pela qual nenhum deles emerge separado, originando confusões e falácias. Foram essas que os sofistas comummente exploraram. Os absurdos mais espectaculares são produzidos pela impossibilidade de separar a leitura existencial ${ }^{7}$ das outras, implicitamente afirmando ou negando a existência, juntamente com os outros sentidos do verbo.

A questão é delicada por distintas, mas convergentes, razões. Adiante veremos não podermos estar certos da proeminência da leitura existencial em muitos paradoxos ${ }^{8}$. Torna-se, portanto, necessário distinguir as dificuldades postas pela compreensão do verbo predicativo, identitativo

noêsai - «via para pensar» - DK31B3.13. Ver ainda C. Kahn, The Verb 'Be' and its Synonyms, Dordrecht/Bóston, 1966, pp. 292-296 (a obra é fundamental para o conhecimento dos usos do verbo, a partir de Homero).

${ }^{5}$ Essa é tese de G. Owen, no clássico «Plato on Not-Being» (Plato I, G. Vlastos (org.), Garden City, 1971, pp. 223-265; reimpresso em Plato I, Gail Fine (org.), Oxford, 1999, pp. 416-454). Lesley Brown «Being in the Sophist: a Syntactical Enquiry» (Oxford Stud. in Anc. Phil. 4, 1986, pp. 49-70, reimp. em Plato I, 455-478) chama a atenção para a implausibilidade desta equivalência, mostrando que nem toda a predicação monádica constitui um uso completo, nem todo o uso completo implica uma leitura existencial. No final, voltaremos a esta questão.

${ }^{6}$ A metáfora da fusão foi cunhada por M. Furth, «Elements of Eleatic Ontology», Journal of the History of Philosophy, 6, 1968, pp. 11-132.

Para o qual o latim cunha o verbo existere, ou exsistere, tornando forçada a utilização do verbo «ser» para a leitura existencial, para a qual as línguas modernas recorrem a «existir».

${ }^{8}$ C. Kahn, «Por que a Existência não emerge como um Conceito distinto na Filosofia Grega?», Sobre o verbo grego ser e o conceito de ser, Rio de Janeiro, s. d., pp. 91-106. 
ou veritativo, das do verbo existencial, pois é a elas a que um leitor actual é mais sensível.

1.2.2. Tentemos compreender como um grego clássico entenderia, por exemplo, o seguinte passo do Eutidemo, de Platão:

«É possível mentir?»

$1)^{9}$ «Dizendo a coisa de que estamos a falar, ou não dizendo?»

......

2) «Portanto, se alguém a diz, não diz nenhuma outra das coisas que são, a não ser aquela que diz?»

......

3) «E esta, que se diz, é verdadeiramente uma só das coisas que são, separadamente das outras?»

......

4) «Portanto, aquele que diz diz aquilo que é?»

5) «Mas a pessoa que verdadeiramente diz aquilo que é e as coisas que são diz a verdade. ...» (283e-284a).

O passo reproduz o início de um argumento em que Eutidemo pretende mostrar a impossibilidade da mentira, logo, também da falsidade e da contradição. 1 faz equivaler a mentira a «dizer o que se está a dizer» (jogando sobre o equívoco referencial nos dois sentidos de legein: «dizer», «falar»). 2, 3 e 4 acrescentam que quem «diz o que está a dizer» «diz o que é», ou seja, 5, «diz a verdade».

$\mathrm{O}$ argumento começa por estabelecer a identidade entre 1, dizer, e 23, afirmar. A referência a algo torna-se equivalente à realidade/verdade do que o discurso afirma, como se o facto de se estar a falar de algo implicasse a verdade do que é dito, mais a identidade, realidade e existência daquilo sobre que é o discurso. 4 reforça a fusão dos sentidos do equívoco e 5 isola o veritativo. Ergo, se a mentira é possível, então é impossível, pelo facto de ter sido dita (vide Crá. 429d-430a).

Em 2, «coisas que são» são coisas que «são isto ou aquilo», que «são verdade» e «que existem». 4 acentua as leituras veritativa, predicativa e

${ }^{9}$ Para facilitar o comentário, numerámos as falas. As reticências indicam a aquiescência do interlocutor. A tradução é de Adriana Nogueira, Platão, Eutidemo, Lisboa, 1999. 
existencial e 5 separa a veritativa. Mas a leitura existencial só é para um leitor moderno. Primeiro, pelo facto de não poder emergir separada, em grego: vide 3, 4, 5; depois, por se poder reduzir ao equívoco entre a identidade e a predicação.

Em síntese, não é possível isolar o sentido existencial do verbo, mas também não é possível exclui-lo. Daqui resulta a dificuldade, pois o tradutor para as línguas modernas tende a recorrer ao verbo «existir», automaticamente anulando a fusão dos predicados e a presença na frase de todos os outros sentidos do verbo.

1.2.3. No Eutidemo, Platão não perde a oportunidade de reforçar argumentos como estes com a descrição do entusiasmo que despertam na assistência, mais interessada em deixar-se enredar em confusões do que em tentar dissipá-las. Todo o diálogo constitui um admirável retrato do espectáculo da estupidez humana. Mas vai muito mais longe do que isso. Constitui também um inventário dos processos usados pelos estúpidos para seduzirem os mais estúpidos e o esboço do roteiro que permitirá escapar-lhes.

Do ponto de vista de um leitor actual, o texto traduzido é, ao invés, absolutamente incompreensível. À primeira leitura, amontoa formulações sem sentido. Todavia, uma vez analisado e compreendida a sua finalidade erística, transforma-se numa curiosidade e no exercício em futilidade que realmente constitui.

1.3. Estará Platão a apresentar uma caricatura da prática sofística, que não poderemos saber até que ponto corresponde à realidade? A leitura de um breve trecho de uma das versões do fragmento 3 , de Górgias ${ }^{10}$, pode ajudar-nos a resolver essa dúvida.

«Pois, se o não ser (to mê einai) é (1) ${ }^{11}$ não ser, o não ser (to mê on) é (2) não menos que o ser (tou ontos). Pois, o não ser (to mê on) é (3) não ser e o ser ser; de modo a as coisas (ta pragmata) serem (4) (einai) nada mais do que não são (5).»

${ }^{10}$ DK82B3a: De Melisso, Xenofane, Gorgia, 5.25-28. O tratado, falsamente atribuído a Aristóteles, é hoje considerado de autor anónimo. Vide Barbara Cassin, Si Parménide, Lille, 1980.

${ }^{11}$ As traduções de einai foram numeradas para facilitar a referência. 
Para além de as repetições tornarem o texto incompreensível ao ouvinte grego, e ainda mais ao leitor que tenha diante de si umas linhas manuscritas, com vogais não acentuadas, sem espíritos, nem sinais de pontuação e espaços a separarem as palavras, é nítido que o argumento visa deliberadamente confundi-lo.

O equívoco dos sentidos predicativo/identitativo $(1,3)$ com os predicativo/existencial $(2,4,5)$ gera o aparente paradoxo ${ }^{12}$. Pois, a conclusão de que as coisas são não mais do que não são é perfeitamente pacífica: um cavalo, por exemplo, é um cavalo e não é um boi ${ }^{13}$.

A questão resulta de a dedução da existência/predicação a partir da identidade ser válida tanto para o ser, como para o não ser, por serem ambos idênticos a si próprios ${ }^{14}$. Mas esta possibilidade gera incontornáveis absurdos, uma vez que são contrários.

Surpreendente será, portanto, a extrapolação do argumento para «as coisas». Se estas forem tomadas como «todas as coisas», a leitura predicativa/existencial deflagra o paradoxo; se, como «cada uma das coisas», será o sentido identitativo responsável por ele, ao assumir a identidade da coisa com o predicado que o seu nome expressa. Seja como for, a cadeia de equívocos entre as coisas que são e as que não são degenera em paradoxo pela fusão da existência/predicação com a identidade: nada pode existir, se for diferente de si próprio ${ }^{15}$.

2. Portanto, a leitura dos dois textos mostra ser a simultaneidade da «fusão» dos sentidos de einai com a emergência das diversas leituras separadas a gerar os paradoxos. Esta conclusão é confirmada pelo facto de um leitor actual, que leia os textos na sua língua, não sentir paradoxo

${ }^{12}$ Simplesmente resultante da identificação do uso completo com a leitura existencial. Mas nada garante a presença desta leitura, pois talvez a diferença nos usos do verbo seja apenas provocada pela elisão dos complementos, em 2, 4, 5.

${ }^{13}$ Foi para resolver problemas destes que a Teoria das Formas terá sido concebida: vide Parm., 129a-130a.

${ }^{14}$ Se os encararmos como nomes das classes das coisas «que são» e «que não são» (Parménides, 2.7, 3, 6.1-2 passim).

${ }^{15}$ Foi para evitar este paradoxo que, supõe-se, Antístenes, ou um pensador anónimo, interditou toda a predicação não identitativa (Platão, Sof., 251b-c; Aristóteles, Met. V 1024b32-33). O interdito abole ainda o equívoco da leitura da negação, como contradição e diferença: Se um cavalo não é um boi, não é; portanto, não é um cavalo e não existe (vide Platão, Eutid., 297d-298e). 
algum. Como pode alguém compos mentis confundir a identidade com a predicação e a existência?

Por essa razão, para tornar os textos inteligíveis, há que levar o leitor a ter a percepção de como reage a estas formulações alguém, para quem os sentidos de «ser» são lógica, mas não linguisticamente, indiscerníveis e que imensamente se espanta com as consequências desta duplicidade. Do esforço resultam dois benefícios: o de proporcionar ao estudioso a compreensão de como pensa uma mente que entende a linguagem de modo diferente do dele; e o de captar o alcance da penosa tarefa de desambiguação e génese conceptual, levada a cabo por Platão e Aristóteles. Observemos, porém, agora o problema, da perspectiva do leitor actual.

2.1. O facto de a maioria das pessoas ter lido os diálogos de Platão, em tradução, antes de eventualmente os vir a ler no original grego, pode condicionar definitivamente a sua compreensão de algumas questões neles tratadas. Considerem-se, por exemplo, as seguintes traduções de dois passos do Fédon:

A 1) «Dizemos que a própria justiça é algo ou nada?»

A 2) «Dizemos que a própria justiça existe ou não?» (65d)

B 1) «Se as coisas de que antes falávamos são, o belo e o bom e todas as entidades como elas,»... «então as nossas almas eram antes de nascermos.»

B 2) «Se existem as coisas,»... «então ... as nossas almas existiam...» (76de).

Nos blocos A e B, 1 e 2 são traduções possíveis do original grego. Como poderão ser entendidas por um leitor que desconheça grego? $\mathrm{O}$ par de traduções 1 é difícil de compreender em português. Em A 1, a pergunta - a justiça (ou qualquer outra) é «algo ou nada» - confere já identidade/realidade à entidade nomeada. Defini-la constitui o problema a resolver, mas a formulação não permite ao leitor aperceber-se do facto. Em B 1, é pior, pois, na primeira parte, a ausência de um complemento («algo») torna a frase incompreensível, em português, dado que o verbo deverá ser lido predicativamente, mas o predicado acha-se elidido; na segunda, a frase é incompreensível.

Em 2, a situação é diferente. A 2 pode ter uma leitura retórica. Mas há uma questão mais profunda, que remete para a compreensão daquilo que implicitamente distingue a «própria justiça», de casos correntes, identifi- 
cados como tal. B 2 é aceitável e faz todo o sentido: «se «as [Formas]» existem, então as nossas almas também existem».

O problema é que, em ambos os casos, a tradução existencial é redutora do sentido do verbo grego (além de incorrecta, em A 2, pelo facto de omitir a tradução do indefinido $t i$, que favorece a leitura copulativa da frase $\left.^{16}\right)$.

E, no entanto, se as duas traduções do mesmo original forem aceites, há que compreender a relação pela qual a «existência» das Formas decorre de «serem algo». Acresce que essa existência não resulta da argumentação - que opõe a identidade das Formas inteligíveis à das suas imagens visíveis - , mas da concordância do interlocutor ${ }^{17}$. No entanto, embora não sejam claras as consequências da concessão da existência a Formas invisíveis, é claro que não dispomos de outro termo, além de «existência», que permita caracterizar o estado em que a alma se encontrava, antes de se unir a um corpo.

2.3. É claro que o leitor de qualquer das traduções não tem qualquer possibilidade de adivinhar os problemas nelas contidos. Para ele, é como se tivesse sido o próprio Platão a escrevê-las. Torna-se, portanto, capital determinar se só uma delas é correcta, qual e por que razão.

E sobre esta questão, não há dúvida. A tradução existencial é redutora e está errada, pelo menos por três razões, dando, além disso, origem a dificuldades filosóficas insuperáveis. Em 65 d, a concessão da existência à justiça e às outras Formas só pode parecer insólita. Por um lado, como dissemos, por não se perceber o estatuto destas entidades, perante as coisas que dizemos existirem, pelo facto de as vermos; por outro, porque a existência não parece ser tópico sobre o qual valha a pena esboçar

${ }^{16}$ A distorção será, porém, desculpável, se a encararmos como uma simplificação da tradução: «Dizemos que existe algo, em si, justo, ou nada?». Idêntica formulação é usada, em 74a: «Dizemos que alguma coisa é igual... o próprio igual?», ou «Dizemos que algo igual existe...?». Este é o expediente usado por Maria Teresa Schiappa de Azevedo na sua tradução do Fédon (Coimbra 1982), por exemplo, a partir de 74a).

A formulação B remata o argumento em que as entidades referidas são apresentadas como «objectos» de um estado cognitivo anterior ao nascimento.

${ }^{17}$ Às perguntas «Dizemos...?», nos dois casos, o interlocutor responde com enfáticas afirmativas, o que mostra que Sócrates busca o seu assentimento. 
acordos: uma coisa existe ou não, independentemente da opinião de alguém sobre esse facto.

Esta mesma razão afasta a possibilidade de interpretar existencialmente os argumentos subsequentes. O primeiro (64e-69e) desenvolve, em duas secções, o dualismo onto-epistemológico, que opõe a alma ao corpo. A vertente epistemológica $(64 \mathrm{e}-67 \mathrm{~b})$ mostra que, enquanto a alma capta os entes inteligíveis pelo exercício da razão, o corpo contacta com o visível através da sensibilidade. A vertente ética (67b-69e) complementaa, denunciando a corrupção da alma, cuja orientação para a virtude e o bem é contrariada pela persistente interferência do corpo, que a atrai para o prazer.

O segundo é o argumento da anamnese (72e-77a), no qual o dualismo é também expresso onto-epistemologicamente. Enquanto o igual inteligível é perfeito e imutável, a sua imagem visível está sujeita à mudança fenoménica, logo à variação doxástica ${ }^{18}(74 b)$. O facto evidencia a anterioridade e superioridade do inteligível. É delas que resulta a necessidade de postular uma vida da alma, separada do corpo, anterior ao nascimento ${ }^{19}$.

Ora esta «anterioridade e superioridade» onto-epistemológicas só pode ser entendida em termos de maior ou menor clareza, de realidade. Mas não de existência, pois esta, como vimos, é insusceptível de gradação ${ }^{20}$. A esta razão acresce a contraprova da impossibilidade de interpretar o argumento em termos da existência das Formas. Mas mais significativo será perceber como a questão da existência é totalmente estranha aos

${ }^{18}$ É a simultaneidade dos três registos - o da instabilidade da coisa percebida, da variação no modo como é percebida e da diversidade das opiniões sobre ela que opõe o sensível ao inteligível. A conjunção destes factores permite-nos caracterizar o argumento como «onto-epistemológico», porque nenhum dos registos se pode tornar independente dos outros.

${ }_{19}$ Pois, se alma contactou com as Formas, só pode ter sido antes de experimentar sensações, não se compreendendo como isso possa ter acontecido depois da sua encarnação num corpo, a não ser pelo exercício da anamnese.

${ }^{20}$ Esta interpretação do argumento foi desenvolvida por G. Vlastos, num artigo clássico, aceite pelo consenso da crítica: «Degrees of Reality in Plato», Platonic Studies, Princeton, 1973, pp. 58-75. A alma não pode «existir» no outro mundo mais do que neste. Por outro lado, passos como Féd. 79c, ou a descrição da «vida supra-celeste», na palinódia do Fedro, dão mais força à vida da alma, enquanto separada do corpo, do que unida a ele. 
argumentos, a toda a argumentação e às conclusões a que o filósofo quer chegar.

Acresce ainda - e este é o aspecto mais grave -, que traduzir «ser» por «existir» redunda na anulação, para o leitor actual, das outras leituras do verbo, tornando a abrangência semântica do verbo grego e das formulações platónicas - bem como a própria teoria das Formas - inacessíveis à sua compreensão.

2.3.1. E a realidade? Vejamos a outra tradução pela perspectiva a ela oposta, perguntando que sentido poderá ter em português a afirmação de que as Formas e a alma «são» (76d-e; vide $76 \mathrm{e}-77 \mathrm{a}^{21}$ ). Poderá Sócrates pretender «demonstrar» a imortalidade da alma sem supor a sua existência?

Em primeiro lugar, não afirmar a existência de algo não equivale a consentir na sua inexistência. Embora a dificuldade seja só de expressão, não repugna no caso da alma falar de existência. Tal como as Formas eram reais $^{22}$, a alma existia, já antes do nascimento, ou seja, da encarnação num corpo.

2.3.2. Testemos então a tradução «ser algo». Que implica e significa ela? Perguntar pela realidade de algo é buscar a sua «entidade» (ousia). Essa entidade é «aquilo que ela é», o «predicado» (passe o aristotelismo) que, no caso de uma Forma, ela supremamente exibe, cuja descrição constitui o seu $\log$ s $^{23}$.

Sustentar que a justiça, etc., «é algo» é encará-la como a entidade que suporta o predicado «justo», de modo perfeito e exemplar, em oposição às muitas imagens da justiça que dela participam, patentes nos homens e nos seus actos ${ }^{24}$. No argumento que expõe o dualismo corpo/alma, «algo» representa a entidade das Formas, investigada pelo raciocínio. Contactar, captar uma Forma só será possível através do exercício da

${ }^{21} \ll \ldots$ que igualmente a nossa alma era antes de nascermos e as entidades de que falas»; «... todas as coisas como estas, o belo, o bom, e os outros de que agora falavas, são supremamente».

${ }^{22}$ Pois a tradução existencial não se estende às Formas. Mesmo assim, é essencial respeitar a relação bicondicional entre as Formas e a alma.

${ }^{23}$ Discurso, frase declarativa, que «diz o que a coisa dita é».

${ }^{24}$ R. E. Allen, «Participation and Predication in Plato's Middle Dialogues» in Studies in Plato's Metaphysics, R. E. Allen (org.), Londres, 1965, pp. 43-60. 
racionalidade, de modo inteiramente alheio e oposto à prática da sensibilidade e à observação dos factos ${ }^{25}$ (99e-100a; vide 65d-69e, 79c).

Finalmente, no argumento da anamnese, «algo» é a Forma, da qual a alma tem uma reminiscência vaga, e mais tarde, mediante a aplicação da metodologia hipotética, deverá ser capaz de recordar perfeitamente. Mas o aspecto mais subtil da teoria da anamnese reside na compreensão do facto de a captação do sensível se dever à estruturação da aparência pela reminiscência das Formas ${ }^{26}$.

2.4. A transposição desta leitura para o dualismo onto-epistemológico da República V só reforça as conclusões atingidas. O paralelismo das «competências» pelas quais sensível e inteligível são explorados (477a-478d) conduz à oposição do saber das Formas, «exemplares perfeitos», às opiniões sobre a multiplicidade oscilante da «aparência sensível» ${ }^{27}$ (478e480a). De resto, a posterior tentativa de superação do dualismo pela prática da dialéctica (VII 532a-535a) só visa enquadrar os exercícios da metodologia hipotética, que o Ménon e o Fédon apresentam.

$\mathrm{O}$ facto de, em todos estes textos, as Formas serem referidas quer através de expressões técnicas recorrentes (eidos, ho estin, auto to, auto kath'hauto e outras), quer pelos seus nomes próprios (Bom, Belo, Justo, etc.) mostra que se manifestam como esse «algo», em cujo «ser» se acha condensada a sua identidade, existência, predicação e verdade. Portanto pelo menos enquanto a ambiguidade onto-epistemológica se mantiver -, não há condições para que algum destes sentidos possa emergir separado.

${ }^{25}$ Este pressuposto, no qual assentam a metodologia hipotética e a teoria da participação, resulta da natureza inteligível do bem e do saber, que não consentem o recurso à sensibilidade e às aparências sensíveis. Esta é a justificação da «segunda navegação» (99a-d), na sequência da qual é referida a metodologia hipotética.

${ }^{26}$ Pois, que outra possibilidade haveria de considerar «igual» aquilo que não só não é igual, como não é igual? É este aspecto que confere à anamnese o estatuto de uma das teorias susceptíveis de explicar a cognição.

${ }^{27}$ A expressão refere o complexo da doxa, condensando num único termo a natureza física da multiplicidade, o meio utilizado para a sua captação e a produto verbal que a sintetiza: a opinião (vide a caracterização das competências: R. V 477d). É precisamente porque as coisas visíveis «são e não são» que se torna necessário recorrer às Formas - «que são o que são» -, para explicar que nos possamos entender sobre o sensível (vide Teeteto, 152a-187a). 
2.5. É a esta impossibilidade de emergência separada de um sentido de «ser» que há que fazer atenção, pois nela reside a diferença que distingue a leitura de, por exemplo, um diálogo de Platão, em grego, da da sua tradução, embora esta impossibilidade não cancele o alcance existencial de uma qualquer formulação ontológica platónica.

Implica, porém, não ser sensato limitar à existência o alcance de uma tese ou de um argumento, pelo facto de não ser plausível que esse sentido do ser seja separadamente pensável, para um grego. Bem ao contrário do que se passa connosco, acrescentemos! Mas as precauções a ter redobram, quando pensamos que pouca ou nenhuma alternativa tem quem só conhece o texto, numa tradução que opta pelo sentido existencial.

3. Resulta desta interpretação a impossibilidade de encontrar nos diálogos qualquer menção da existência? Evidentemente que não poderemos fazer tal afirmação enquanto não tivermos examinado o conjunto da obra platónica. Mas não será preciso tanto, pois basta-nos um único contra-exemplo para que a tese se ache refutada.

3.1. É consensual entre os comentadores de Platão que o grupo Parménides, Teeteto, Sofista, Político não se enquadra na onto-epistemologia dos diálogos em que é exposta a teoria das Formas. Em quê exactamente reside a diferença e que razões a justificam, sobre isso não há acordo entre os comentadores. Mas bastará referir as dúvidas lançadas sobre a T. F., no Parménides, a ausência de uma referência explícita a Formas, no Teeteto, as dúvidas sobre a tradução de eidos, a par das críticas aos «amigos das Formas», no Sofista, para ter uma ideia de que pode estar em causa o abandono da Teoria.

O modo como a questão se manifesta no Parménides é da maior relevância para a questão, mas as dúvidas da crítica sobre a interpretação do diálogo não favorecem que a ele façamos recurso. Também sobre o Teeteto há dúvidas. Mas aí a investigação assenta no saber, não no ser. Felizmente, é outra a abordagem do Sofista, embora as perguntas do Teeteto continuem de pé. Como se distingue o falso saber do verdadeiro? Que relação mantém com a opinião (233c)?

3.1.1. A escolha do sofista como tema do diálogo obriga a responder a uma série de questões ligadas à linguagem: a natureza da imitação (235bc), da aparência (236c), da verdade e falsidade (236e), em suma, do ser e do não ser (237a sqq). Pois encontrar a falsidade nas opiniões e nos discursos implica conferir ser ao não ser (241a-b). Mas, por sua vez, esta contradição obriga à definição de cada um dos termos nela envolvidos. 
Por isso, a definição de ser como potência activa ou passiva, em 247d-e, orienta a investigação para a explicação de como a actividade e a passividade se conjugam na produção do real.

4. O argumento começa com a postulação do ser e a constatação da dupla realidade do movimento e do repouso, física e ideológica (248d249e), voltando-se para a determinação do regime de relações que ligam estes três géneros. Na sua primeira secção (250a-d), movimento e repouso são definidos como «o mais opostos», embora ambos sejam. Todavia, como, do facto de serem, não resulta que ambos sejam movimento ou repouso, nem que o ser «por natureza» se mova ou se ache em repouso, conclui-se que o ser é uma terceira entidade, ao lado e diferente deles.

Após uma interrupção ${ }^{28}$ (250d-254d), o argumento recomeça (254d255d). O ser mistura-se com os outros dois, enquanto eles não se misturam um com o outro. Logo, para que o ser não se dissolva, é necessário que cada um dos três seja o mesmo, em relação a si próprio, e outro, em relação aos restantes. Deste modo são introduzidos mais dois géneros - $\mathrm{o}$ mesmo e o outro -, totalizando cinco ${ }^{29}$.

A última secção do argumento é dedicada ao exame da natureza do não ser e às consequências da sua admissão (255e-258e). O facto de tanto o movimento, como o repouso, participarem do mesmo e do outro, não implica que sejam o mesmo e o outro ${ }^{30}(254 \mathrm{~b})$, pois o ser não é o mesmo (255b-c), nem o outro (255c-d).

${ }^{28} \mathrm{O}$ raciocínio é intercalado com comentários que visam estabelecer os princípios da investigação. Estes desempenham uma função contextualizadora, fazendo apelo às teorias cosmológicas relevantes (252a-c), e reguladora, questionando o interdito de mistura dos géneros (251a-c, 252c, 252d) e estabelecendo as modalidades da sua relacionação (253a-e): verticalmente, inclusão/exclusão; horizontalmente, participação/separação.

Sobre a importância do passo para a compreensão da concepção do ser como dynamis, vide L. Brown, «Innovation and Continuity: the Battle of Gods and Giants: Sophist 245-249» in Method in Ancient Philosophy, Jyl Gentzler (org.), Oxford, 1998, pp. 181-208.

${ }^{29}$ Pois nem o mesmo, nem o outro, se confundem com o ser. O mesmo, porque isso implicaria que o repouso e o movimento fossem o mesmo (255b-c). O outro, pelo facto de a sua natureza ser - diferentemente da dele - puramente relativa (255d).

${ }^{30}$ Por analogia com o início do argumento, em que o poder da participação tinha sido transmitido pelo ser. 
É esta natureza do outro que lhe permite permear os restantes, fazendo cada um deles outro em relação a ele, nomeadamente o ser. Pois, se o movimento ao mesmo tempo é e é outro em relação ao ser, reciprocamente, em relação ao movimento, o não ser é ${ }^{31}$ (256d), tal como em relação a todos os outros (256e). O único modo de superar a contradição consiste na reformulação da negativa, que passa, de ser interpretada como contrariedade $^{32}$, a ser lida como alteridade (257b).

O epílogo introduz as mais dramáticas inovações. Definido o discurso (logos) como entrelaçamento das Formas (259e) - o que permite enquadrá-lo na análise anterior, articulando os planos ontológico, epistemológico e lógico -, fica estabelecido que:

1. Combina um nome com um verbo (261e-262e);

2. É dito «de alguém» (262e);

3. É verdadeiro ou falso (262e-263b, 263c-d).

Torna-se então possível atingir uma série de conclusões (263e-264b), que permitirão definir a natureza do sofista:

1. O discurso é a expressão verbal do pensamento (dianoia);

2. Consiste na afirmação e negação;

3. Enquanto não verbalizado, é opinião;

4. Esta pode ser verdadeira e falsa;

5. Associado à sensação, constitui a aparência (phantasia);

6. Consequentemente, a falsidade é possível.

4.1. Exposto o argumento, passemos à sua avaliação. Na primeira secção, a grande interrogação é a da natureza do ser. Vemo-la expressa no poder de «envolver» (250b) os outros dois, fazendo-os participarem dele, sem, contudo, se deixar afectar pelas suas respectivas potências.

A segunda questão é a da emergência dos dois novos géneros. Se o ser tem o poder de se misturar com os outros dois, como se compreende que continuem a ser três? É para explicar esta persistência que o mesmo e o

${ }^{31}$ Se o ser é e é outro em relação aos outros géneros, estes são, por participarem do ser, e não são, por serem diferentes dele, constituindo colectivamente o não ser. $\mathrm{O}$ argumento mostra que o não ser é diferente do outro, dada a natureza relativa deste $(255 \mathrm{c}-\mathrm{d})$.

${ }^{32}$ Sendo a contrariedade erradicada da relação entre ser e não ser (258e). 
outro são chamados ao argumento ${ }^{33}$, forçando a redefinição das relações entre os cinco.

A terceira questão - a da natureza do outro - é a que acarreta consequências mais espectaculares. Pelo facto de ser outro em relação ao ser, o outro é não ser. Desta conclusão resulta a tese que condensa todo o argumento: a de que o não ser é.

Até aqui - e durante mais um pouco - o argumento constitui uma análise da realidade. Mas, de repente, volta-se para o discurso, introduzindo a reformulação da negativa como alteridade ${ }^{34}$. De modo que, a partir deste ponto, aplica ao discurso as conclusões da análise anterior.

Todavia, regressando ao seu início, percebemos que sempre constituiu uma análise paralela do discurso ${ }^{35}$. Pois - aceitando a definição deste como «entrelaçamento das Formas» (259e) -, nenhuma possibilidade haverá de entender o uso da expressão «é», senão com o recurso ao ser. Esta tese obriga-nos a questionar o sentido de «ser» e dos restantes sumos géneros em todo o argumento estudado.

4.2. Em cada uma das secções em que se divide o argumento, um dos géneros assume o protagonismo. Na primeira, como dissemos, o ser exibe a potência que lhe permite envolver movimento e repouso, levando-os a participarem dele, sem se deixar afectar pelas potências deles. Na segunda, cabe ao mesmo apresentar-se como suporte da identidade de cada género. Na terceira, é o outro que patenteia a sua natureza «despedaçada», pelos outros géneros e por «todas as coisas» (258d8-e1).

Extrapolando os resultados desta análise para o plano do discurso, damo-nos conta da tarefa que levou a cabo. Por um lado, reunindo, por outro, dividindo a potência do ser, funda, pela ordem inversa, através do outro, o uso predicativo (256d-258e), através do mesmo, o uso identitativo $(255 \mathrm{a}-\mathrm{c})$ - distinguindo um do outro -, apontando, através do ser, à

${ }^{33}$ Pois cada um deles é o mesmo em relação a si próprio e outro em relação aos restantes.

${ }^{34}$ Esta reformulação já era efectiva desde o momento em que o outro é incluído nos cinco sumos géneros. Mas, na realidade, já condiciona toda a investigação desde o início do debate sobre a opinião falsa, no Teeteto (188a-c).

${ }^{35}$ Que será possível fazer recuar à refutação da primeira resposta de Teeteto, no Teeteto, 184b-187a. 
questão da existência (250b-d, 254d-255c, 256a $1^{36}$ ). Quanto ao uso veritativo, é finalmente desambiguado pela remissão da verdade, do plano semântico para o lógico, como «qualidade» das proposições (262e-263d).

4.2.1. A caracterização dos dois primeiros usos e o afastamento do quarto são indiscutíveis. A do terceiro, porém, não é convincente. A natureza da «existência» é estabelecida em três momentos, coincidentes com as secções em que se divide a apresentação do argumento. No primeiro, manifesta-se como potência para acolher a participação de tudo o que é. No segundo, na impossibilidade de essa potência ser reduzida à identidade. Na terceira, a potência de «ser participado» volta a manifestar-se, mas agora na relação do ser com o não ser: tanto no que é, como no que não é (ou que «é outro»).

4.2.1.1. Vale a pena apreciar a subtileza deste último argumento. Não há dúvida de que o outro regula a possibilidade da predicação não identitativa $^{37}$, atribuindo ao mesmo a responsabilidade por esta última. A desambiguação da verdade será, como também vimos, resolvida mais adiante.

Portanto, resta a questão da existência, que recebe a sua atenção em 236-241, a partir da impossibilidade de caracterização do não ser. Mas a abordagem não implica que o argumento tenha chegado a separar a leitura existencial do verbo. Apesar de o passo em que a inexistência é

${ }^{36}$ Num artigo clássico «Plato and the Copula: Sophist 251-259» (reproduzido em Studies in Plato's Metaphysics, R. E. Allen (org.), 1965, pp. 207-218), J. Ackrill sustenta, contra Cornford (Plato's Theory of Knowledge), que a leitura existencial é imposta pela fórmula: dia to metechein tou ontos - 256a1. A interpretação de Ackrill não conseguiu resistir às críticas de Owen (op. cit.), que provaram ser possivel reinterpretar as alegadas leituras existenciais como predicativas elípticas.

Obviamente, simpatizando com o sentido desta interpretação, não nos sentimos tão confiantes de que, por si, a fórmula estabeleça a leitura existencial, mais do que afirme a realidade do movimento. Voltaremos à questão em post scriptum.

${ }^{37}$ A finalidade mais ampla da análise de Platão é mostrar que os sumos géneros se combinam, insistindo particularmente na rejeição dos «recém-chegados ao saber», que, como dissemos atrás, só admitem a predicação identitativa (251a-252e). 
afastada - o Estrangeiro confessa que dela já «há muito deixou de falar» (258e, 259a-b) -, mostrar que o filósofo tem consciência do problema ${ }^{38}$.

4.3. Comparando este resultado com o que os passos que atrás estudámos, do Fédon, nos ensinaram, parece-nos ser impossível qualquer confusão. Este ser já não é «algo». Na abrangente designação que a tradição lhe conferiu, mantém a unidade do seu significado. Mas o substantivo que o nomeia acabou por encontrar, na análise da diversidade das relações que mantém, a capacidade de separar os sentidos do verbo homónimo, da ambiguidade do qual nasceu.

Todavia, só poderemos abarcar a magnitude das consequências da tarefa realizada, ensaiando a comparação com as referências aos sofistas, atrás feitas. Platão deu-se conta do facto de a ambiguidade de einai constituir uma grave deficiência, um entrave ao progresso do saber e uma oportunidade, aproveitada por um punhado de «espertalhões» para se atribuírem um estatuto, para ele imerecido ${ }^{39}$.

Pensamos que a versão canónica da T. F. constitui já uma tentativa séria de entender o «ser» como a realidade, construindo, a partir da lição de Parménides, uma concepção de saber coerente e uma metodologia de investigação aplicável. Todavia, a formulação da teoria num corpo textual escrito proporcionou, pela primeira vez na história do pensamento, uma oportunidade ao exercício da crítica.

A análise levada a cabo no Sofista porventura reflecte o momento mais alto dessa crítica $^{40}$, da qual o Parménides e o Teeteto constituem os antecedentes. Mostrámos que é aí levada a cabo uma tarefa de desambiguação dos sentidos de einai e de to on. Argumentámos que o isolamento da noção de «existência» será um dos resultados por ela atingidos. Mas não há como estar certo da justeza dessa conclusão.

${ }^{38}$ G. Owen, op.cit, pp. 423-427, aproveita este mesmo indício para chegar à conclusão oposta.

${ }^{39}$ A algumas justificações pontuais deste diagnóstico preferimos a denúncia do escândalo que o Eutidemo constitui. O termo entre aspas, pretende ser uma tradução não muito exagerada de deinos, com que os sofistas costumavam ser designados.

${ }^{00}$ A circunstância de se tratar de uma autocrítica não nos parece implicar a renúncia global à substância da concepção examinada. Poderá ser encarada como uma revisão, uma mudança de perspectiva, ou ambas. 
5. Seja como for, tal possibilidade fornece o missing link para a filosofia de Aristóteles. Pois não cremos que ela seja compreensível sem a fixação da existência, como conceito operatório da investigação da realidade. Podemos notá-lo, primeiro, na compreensão de um sujeito a partir do «que existe nele»; depois, na proibição de atribuir seja o que for ao que quer que seja, se não existirem sujeitos, «substâncias primeiras» (Cat. 1).

5.1. As «expressões compostas» são definidas a partir do cruzamento dos dois vectores: o que «existe num sujeito» e o que «se diz de um sujeito». Existe e diz-se de um sujeito o Acidente Substancial (AS); existe, mas não se diz do sujeito, o Acidente (A); diz-se, mas não existe num sujeito, a Substância Segunda (S2); não se diz, nem existe num sujeito, a Substância Primeira (S1).

S1 não existe, nem se diz de um sujeito, porque é o próprio sujeito. Sem S1, nada poderia existir ou dizer-se, porque não haveria sujeitos. Sem AS o sujeito não poderia existir, como tal, e ser conhecido, pois AS exprime o predicado pela posse do qual ele é e é chamado aquilo que é. Sem S2, o sujeito não poderia ser relacionado com outros, pois dele não poderia dizer-se o que tem ou não em comum com eles. Sem A, pelo contrário, o sujeito não se distinguiria de qualquer outro, pois não poderia ser individuado ${ }^{41}$.

5.2. Depois do Estagirita, a existência não mais desaparecerá quer do vocabulário, quer das preocupações dos filósofos. Terá ainda um longo caminho a percorrer, até chegar à análise a que será submetida ao longo do séc. XX. Nem Platão, nem os textos platónicos, terão - a nosso ver alguma coisa a ver com isso. Mas à análise do Sofista se deverá o isolamento dos outros sentidos do verbo. Mais nada pretendemos.

6. Com esta conjectural análise procurámos realizar o arriscado exercício de mostrar como um termo pode mudar de sentido numa obra, sem que o seu autor expressamente disso nos advirta. E como poderia fazê-lo, perguntemos, se não dispõe de terminologia adequada para tal?

A dificuldade reside na circunstância de pretendermos traduzi-lo por um outro termo, ainda não inventado, no momento da composição da obra, nem pensável na língua e na cultura em que ela se insere.

${ }^{41}$ Com este oposição, Aristóteles separa os predicados definidores da essência (AS) dos (A) que transitoriamente distinguem os entes em que ela se acha presente. 
Há que ter em mente que a filosofia grega trabalha com um vocabulário original, que, ao longo dos séculos, a tradição actualiza problematizando, inserindo-o sempre em novos contextos, reforçando este efeito através da tradução. De resto, se quisermos conferir unidade à tradição filosófica, talvez possamos encontrá-la no trabalho de inovação e crítica conceptual que cada pensador realiza sobre as obras dos que o antecedem. A circunstância de termos visto Platão realizá-lo sobre a sua própria obra parece-nos perfeitamente justificada.

\section{Post scriptum}

A polémica em torno da desambiguação do sentido existencial de einai obriga-nos a reexaminar alguns aspectos da proposta acima avançada.

A interpretação da expressão dia to metechein tou ontos (256a1), por J. Ackrill (op. cit.), como uma paráfrase do sentido existencial do verbo, foi negada por G. Owen (op. cit.), para quem nenhum dos usos de einai, no Sofista, é completo, portanto, existencial. Esta posição é confirmada por M. Frede (Prädikation uns Existenzaussage, Hypomnemata 18, Göttingen 1967) e, contradita por R. Heinaman («Being in the Sophist», Archiv für Geschichte der Philosophie, 65, 1983, 1-17).

Todas estas contribuições são avaliadas por L. Brown («Being in the Sophist»), que restabelece a interpretação de Ackrill, por um lado, aceitando a crítica de Owen, por outro, rejeitando a identificação do uso completo com a leitura existencial. É deste estudo que partimos, nesta reavaliação da interpretação proposta.

A estratégia de Owen, seguida por Frede, passa pelo exame de todos os passos do diálogo em que se encontram leituras completas de einai, supostas existenciais, mostrando tratar-se, na realidade, de predicativas elípticas (portanto, usos incompletos).

Uma tal redução do argumento contraria o sentido do texto, dado haver contextos dialécticos (nomeadamente 236-241, 245-249), que se tornam incompreensíveis se a leitura existencial for erradicada. Em defesa desta intuição, Heinaman reexamina algumas propostas de Owen e Frede, 
vindicando a leitura existencial, nalguns passos capitais $(240 \mathrm{e}, 255 \mathrm{c}-\mathrm{d}$, 256d8-e6: op. cit.: 4-6, 14, 7-8 $8^{42}$ ).

Mas o passo em frente na polémica é dado por Brown. A sua leitura difere, por um lado, das de Owen e Frede, por outro, da de Heinaman, por contestar a interpretação da leitura existencial, por eles: enquanto para os primeiros, existencial é um uso completo do verbo, que não tem, nem admite complemento, para ela, é um uso completo que não tem um complemento, explícito ou elidido, mas o pode admitir (459 passim).

Mas faz reservas, quanto à admissão da existência no Sofista. A substância da sua proposta acha-se condensada na tese de que:

«X é F» implica «X é»e «X é» implica «X é F», sendo «X não é» equivalente $\mathrm{a} \ll \mathrm{X}$ não é coisa nenhuma» (477).

Daqui conclui que:

«... em $255 \mathrm{c}$-d, Platão chama a atenção para os usos completos e incompletos de «é», negando embora que tal equivalha à descoberta da distinção fundamental entre a existência e a cópula» (478).

Do nosso ponto de vista, embora Platão mostre ter consciência da distinção entre as leitura completa ( $X \mathrm{X}$ é») e incompleta ( $\mathrm{X}$ é $\mathrm{F} »)$, nunca chega a esclarecer que «X é F» é compatível com «X não é» (por exemplo, «Tróia é famosa»e «Tróia não existe» ${ }^{43}$ ). Esta conclusão permite-nos atribuir ao Sofista um contexto do qual a questão da existência não pode ser retirada, embora daí não se siga que Platão tenha chegado a isolar a leitura existencial de einai.

Para nós, esta concessão é bastante para argumentar que há uma profunda diferença entre a ontologia do Fédon, República, etc. e a do Sofista. A noção de «existência» é totalmente alheia a uma concepção em que sempre «o ser é (algo)». Mas acha-se implícita numa outra, em que,

${ }^{42}$ Heinaman é criticado por J. Malcolm «Remarks on an Incomplete Reading of Being in the Sophist», AGPh, 67 (1985), 162-165.

${ }^{43}$ Vide G. Vlastos, «A Metaphysical Paradox», Platonic Studies, Princeton, 1973, p. 47; L Brown, op. cit., p. 462. Veja-se, pelo contrário, Aristóteles, para quem, de «Homero é poeta» não se segue «Homero existe» (De Int. 21a25-28) e «é necessário que uma coisa seja, para saber o que ela é» (Apost. 92b4-8; Brown, p. 478). 
embora o ser (as Formas) continuem a «ser algo» - pelo regime de relações entre os cinco sumos géneros -, se admite que o «ser» lhes confere existência, bem como a todas as coisas. Pois, enquanto nestas («a geração») «O corpo participa pela sensação», nas outras (o «ser real»: ontôs ousian), a alma participa pelo pensamento (logismou: 248a).

José Trindade Santos

Faculdade de Letras da Universidade de Lisboa

Alameda da Universidade

1600-214 Lisboa

trindad@mail.telepac.pt 